\section{Review Article}

Korean J Transplant 2020;34:71-77

https://doi.org/10.4285/kjt.2020.34.2.71

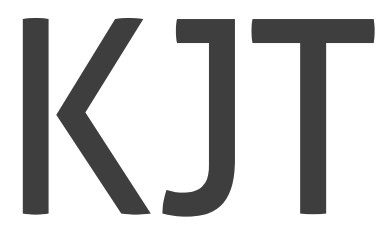

pISSN 2671-8790

elSSN 2671-8804

\title{
Transplantation in Asia during the coronavirus disease-19 (COVID-19) pandemic: briefs from member countries of the Asian Society of Transplantation
}

Terence Kee ${ }^{1}$, Jong Cheol Jeong ${ }^{2}$, Jongwon $\mathrm{Ha}^{3}$, Harun Ur Rashid ${ }^{4}$, Nura Afza Salma Begum ${ }^{4}$, Maggie K.M. Ma ${ }^{5}$, Vivek Kute ${ }^{6}$, Kenji Yuzawa Rosnawati Yahya ${ }^{8}$, Ghazali Ahmad ${ }^{9}$, Lkhaakhuu Od-Erdene ${ }^{10}$, Dibya Singh Shah ${ }^{11}$, Romina A Danguilan ${ }^{12}$, Curie $\mathrm{Ahn}^{13}$, Devinder Singh Rana ${ }^{14}$

\footnotetext{
'Department of Renal Medicine, Singapore General Hospital and SingHealth Duke-NUS Transplant Centre, Singapore ${ }^{2}$ Department of Internal Medicine, Seoul National University Bundang Hospital, Seongnam, Korea

${ }^{3}$ Department of Surgery, Seoul National University College of Medicine, Seoul, Korea

${ }^{4}$ Department of Nephrology, Kidney Foundation Hospital and Research Institute, Dhaka, Bangladesh

${ }^{5}$ Department of Medicine, Queen Mary Hospital, Hong Kong

${ }^{6}$ Department of Nephrology and Clinical Transplantation, Institute of Kidney Diseases and Research Center and Dr. H L Trivedi Institute of Transplantation Sciences, Ahmedabad, India

${ }^{7}$ Department of Transplantation Surgery, National Hospital Organization Mito Medical Center, Ibaraki, Japan

${ }^{8}$ Department of Nephrology, Kuala Lumpur Hospital, Kuala Lumpur, Malaysia

${ }^{9}$ Department of Cardiology, National Heart Institute, Kuala Lumpur, Malaysia

${ }^{10}$ Organ Transplantation Center, First Central Hospital, Ulaanbaatar, Mongolia

"Department of Nephrology, Tribhuvan University Teaching Hospital, Kathmandu, Nepal

${ }^{12}$ Department of Nephrology, National Kidney and Transplant Institute, Quezon, Philippines

${ }^{13}$ Department of Internal Medicine, Seoul National University College of Medicine, Seoul, Korea

${ }^{14}$ Institute of Renal Sciences, Sir Ganga Ram Hospital, Delhi, India
}

Received May 18, 2020

Revised June 6, 2020

Accepted June 7, 2020

Corresponding author: Terence Kee Department of Renal Medicine, Singapore General Hospital, Level 3, The Academia, 20 College Rd, Singapore 169586, Singapore Tel: +65-97539124

Fax: $+65-63214436$

E-mail: terence.kee.y.s@singhealth.com.sg

(c) The Korean Society for Transplantation This is an Open Access article distributed under the terms of the Creative Commons Attribution Non-Commercial License (http://creativecommons.org/licenses/ by-nc/4.0/) which permits unrestricted non-commercial use, distribution, and reproduction in any medium, provided the original work is properly cited.
The coronavirus disease-19 (COVID-19) pandemic has affected 1,029,968 people in Asia as of May 16, 2020. Although Asia was the first continent to be affected, many countries in the region continue to battle COVID-19, which challenges the way transplant programs provide their services. Given the diversity of healthcare systems in Asia, the countermeasures in response to COVID-19 are as potentially diverse. This review reports the experiences of transplant services in member countries of the Asian Society of Transplantation (AST) as well as provides a platform for sharing of best practices during the COVID-19 pandemic. AST invited member countries to provide a short description of their transplant experiences during the COVID-19 pandemic. Whenever information is available, countries were asked to provide information on COVID-19 related statistics, status of transplant programs, mitigation measures taken to prevent COVID-19, and other areas of transplant programs impacted by COVID-19. Ten countries responded to the invitation of which seven still have active transplant programs at varying levels of activity. All countries have protocols for donor/recipient screening and countermeasures to prevent COVID-19 infections in recipients and healthcare providers. Interestingly, these countries report only 16 transplant recipients with COVID-19 infection but no cases of donor-transmitted COVID-19 infection. Despite the diversity of healthcare systems in Asia, transplant centers in Asia have taken appropriate precautions to avoid COVID-19 infections, though the long-term impact of COVID-19 remains unclear.

Keywords: COVID-19; Transplantation; Asia; Donation; Surgery; Infections 


\section{HIGHLIGHTS}

- During the coronavirus disease-19 (COVID-19) pandemic, most countries from Asia in this report are still continuing transplantation activities but selectively.

- All countries have protocols to screen for COVID-19 in donors and recipients.

- Transplantation is significantly reduced as resources are diverted to combat COVID-19.

\section{INTRODUCTION}

As of May $16,2020,22.7 \%$ of the $4,179,091$ cases of coronavirus disease-19 (COVID-19) reported and $8.7 \%$ of COVID-19 related deaths were from Asia [1]. Although Asia was first to be hit by COVID-19, many countries remain in varying stages of the pandemic as a result of differences in responses to test, control and treat COVID-19. Emerging data suggests posttransplant COVID-19 infection to be a serious complication. For example, pooled data from China and Italy found that $27 \%$ of severely infected COVID-19 patients needed assisted ventilation and had a mortality rate of $21 \%$ [2-10]. There are few reported cases of transplant recipients with COVID-19 but deaths have been reported in bone marrow and liver transplant recipients [11-13]. Organ donation and transplant programs have also been severely affected but the extent of its disruption in Asia has not been documented. As a result, the Asian Society of Transplantation (AST) invited member countries to share COVID-19 related statistics (Table 1) and report their experience with transplantation during the COVID-19 pandemic.

\section{BANGLADESH}

In Bangladesh, only one transplant center remains fully active. Donor and recipients are not routinely screened for COVID-19 unless they are symptomatic. So far, there have been no donors diagnosed with COVID-19 or transmitting COVID-19 to their recipients. Kidney transplantation procedures are being performed with separate procurement and implantation teams in dedicated operating theaters. Postoperatively, patients are managed in isolation rooms with dedicated doctors and nurses. The frequency of intervention by healthcare providers are limited to the essentials in order to minimize contact with the recipients.

Bangladesh is in a lockdown so any follow-up is only for emergencies. Transplant recipients are encouraged to contact their transplant healthcare providers via telephone or video call. If they need to come to the clinic, they are requested to wear a mask, be screened for fever, and practice hand hygiene and social distancing. They are assessed in a clean outpatient room by doctors who wear personal protective equipment while maintaining social distancing. At the same time, the attending consultant provides further advice via video call. No prophylaxis is

Table 1. COVID-19 cases and related transplant statistics in Asia (as of April 15, 2020)

\begin{tabular}{|c|c|c|c|c|c|}
\hline Country & $\begin{array}{l}\text { Date of first case of } \\
\text { COVID-19 in } 2020\end{array}$ & $\begin{array}{l}\text { No. of COVID-19 } \\
\text { cases in the country }\end{array}$ & Activity of transplant programs & $\begin{array}{l}\text { No. of transplants } \\
\text { performed during Jan } \\
\text { to Mar } 2020\end{array}$ & $\begin{array}{l}\text { No. of COVID-19 } \\
\text { infected transplant } \\
\text { recipients }\end{array}$ \\
\hline Bangladesh & Mar 8 & 1,231 & Most inactive & 50 & 0 \\
\hline Hong Kong & Jan 23 & 1,017 & Only living donor program inactive & 34 & 1 \\
\hline India & Jan 30 & 11,933 & Most inactive except urgent transplants & Not available & 2 \\
\hline Japan & Jan 15 & 8,640 & Most inactive except urgent transplants & 318 & 4 \\
\hline Malaysia & Jan 25 & 5,182 & Only living donor program inactive & 52 & 0 \\
\hline Mongolia & Mar 10 & 30 & All inactive & 12 & 0 \\
\hline Nepal & Jan 24 & 16 & All inactive & 49 & 0 \\
\hline Philippines & Jan 30 & 5,660 & All inactive & 212 & 6 \\
\hline Singapore & Jan 23 & 3,699 & Only living donor program inactive & 9 & 1 \\
\hline South Korea & Jan 20 & 10,613 & Most programs are active & 1,040 & 2 \\
\hline
\end{tabular}

There has been no reported case of coronavirus disease-19 (COVID-19) infection in organ donors nor deaths from COVID-19 infected transplant recipients. 
given to transplant patients for COVID-19 but they are given advice on how to avoid exposure to COVID-19. Transplant staff are trained on how to take precautions against COVID-19. All non-essential travel between hospitals are restricted except for key members of the transplant team like surgeons and anesthesiologists. So far, there have been no reported COVID-19 infections among the 1,100 kidney transplant recipients in Bangladesh upon follow-up.

\section{HONG KONG}

All transplant programs in Hong Kong remain active except the living donor kidney transplant service, which has been suspended since mid-February 2020. Deceased donors are screened for COVID-19 infection only if they have a history of recent travel or positive contact. In addition, transplant candidates are advised to forego transplantation within 14 days of return from travel.

Outpatient follow-ups of transplant recipients continue but visit frequency is reduced for stable patients. One of the consequences of the border closures is that some transplant recipients became stranded in China. Fortunately, the Hospital Authority of Hong Kong located these patients and arranged for the delivery of immunosuppressive drugs and other essential medications to them. From mid-March onwards, medical staff who returned from overseas travel were instructed to refrain from going to work for 14 days and undergo self-isolation at home. There is one kidney transplant recipient who was infected with COVID-19. This patient was treated with lopinavir/ritonavir and achieved viral clearance despite continuation of immunosuppressive drugs.

\section{INDIA}

Elective living donor organ transplants and non-urgent deceased donor organ transplants are temporarily suspended. However, emergency lifesaving transplants can still be performed with informed consent and appropriate assessment of COVID-19 infection in recipients and donors. Potential donors with positive epidemiological, clinical, or laboratory criteria are not accepted as donors. So far, there are no reports of any donor-transmitted COVID infections. Similar to the general population, transplant recipients are advised to strictly follow the travel advisories issued by the government. Transplant units are also advised to consider ways to limit hospital attendance for stable patients. Immunosuppression for prophylaxis is not reduced during this period, but hydroxy-chloroquine prophylaxis is prescribed only for high-risk patient populations. So far, only two kidney transplant recipients have been infected with COVID-19 but are fortunately stable.

With respect to infection control, information is disseminated to staff and the community to educate them regarding the symptoms of COVID-19. They are also advised on how to ensure proper social distancing and personal hygiene. Health care workers are split into different teams to cover asymptomatic patients, symptomatic patients and COVID-19 infected patients. There are also teams for telemedicine and for standby to cover for manpower shortages. All suspected/confirmed COVID-19 cases are admitted to designated COVID hospitals or isolated at home. There are also COVID-19-related guidelines for controlling human traffic at hospital entrances, identification and shunting of people at risk of infection, temperature recording, hand washing, wearing proper masks, machine disinfection, environmental cleanliness, and self-monitoring of health care workers [14].

\section{JAPAN}

Live-saving transplantations for the heart, lung, and liver with status 1 indications continue with informed consent regarding the risks of COVID-19 infections. However, kidney, pancreas, and intestinal transplantation are suspended. According to the Japanese Society of Transplantation (JST) guidelines, all deceased donors undergo severe acute respiratory syndrome coronavirus 2 (SARSCoV-2) nucleic acid testing (NAT) and are checked for COVID-19 infection or exposure to COVID-19-related risk factors. Whenever possible, it is advised that organ recovery should be performed by the local procurement team and the transplant team should minimize exposure to any COVID-19 related risks. JST also recommends all living donors and candidates of kidney, lung and liver transplants to stay at home or at the hospital for 14 days prior to the transplantation procedure. In hospitals where NAT for SARS-CoV-2 is available, it is recommended to be done on day-14 and day- 1 for both donors and recipients. 
In addition, computed tomography (CT) thorax screening is also recommended for both donors and recipients before the transplantation procedure.

The JST recommends that the prevalent population of transplant recipients be educated about precautionary measures against COVID-19. JST also recommends reduction of the frequency of outpatient visits, provision of additional medications to patients in case of a lockdown in their area of residency, and telephone consults and delivery of medications to patients in their homes to reduce exposure to COVID-19. JST also advises hospitals to develop their own institutional policies on how to care for transplant recipients with COVID-19 infections. So far, there are four kidney transplant recipients with COVID-19 in Japan, of which three are stable and one remains in the intensive care unit.

\section{MALAYSIA}

All transplantation programs in Malaysia remained active until March 20, 2020, when the Ministry of Health directed the living donor transplant program to be suspended. Following a sharp rise in the number of COVID-19 cases, Malaysia enforced a Movement Restriction Order since March 18, 2020. Various measures have been taken to reduce exposure and transmission to COVID-19. These include reducing frequency of clinic visits for stable transplant recipients and remote monitoring of laboratory tests. For patients who are less than 6 weeks posttransplant or with medical issues, they are seen in designated areas of the clinic. Screening for respiratory symptoms, fever, and travel history are enforced at all entrances to hospital buildings, while social distancing is observed in the clinic waiting areas.

Up to April 7, 2020, there were no reported cases of COVID-19 infection involving any transplant recipient or transplant professional. In early February this year, two asymptomatic Malaysians underwent living-donor kidney transplants in Wuhan, China, and presented for follow-up in Malaysia. Both of them were isolated in a designated ward in Hospital Kuala Lumpur to be observed. Fortunately, they both tested negative for COVID-19.

\section{MONGOLIA}

Transplantation activities in Mongolia have been suspended since the first case of COVID-19 infection. There are 583 transplant recipients and the main goal is to prevent COVID-19 infection in this population. There are guidelines on the monitoring of recipients to prevent COVID-19 infection, which include the implementation of virtual clinics and following public recommendations from the Ministry of Health and the Government. However, if patients are required to visit the hospital physically, they are requested to wear a face mask, adopt strict hand hygiene, and check their temperature. As there has been no COVID-19 infections in the transplant or donor population yet, approaches to immunosuppression remain unchanged.

\section{NEPAL}

All transplant programs have been suspended following the lockdown of Nepal on March 24. Most follow-up consults are performed by telephone or video calls and urgent consults are channeled through the emergency department. If patients require hospital visits, they are screened for fever, respiratory symptoms, and contact history.

Patients are counseled on hand hygiene, social distancing and use of face masks. No medications are used for prophylaxis against COVID-19 in transplant recipients. Active case detection and contact tracing are being done, while test facilities for COVID-19 have been expanded all over the country. The government has also designated 101 hospitals as COVID Hospitals for the isolation and management of COVID-19 suspects and positive cases.

\section{PHILIPPINES}

As the number of COVID-19 cases grew, the island of Luzon, where majority of transplant activities occur, underwent lockdown on March 16, 2020. As a result, all transplantation activities were ceased out concerns regarding possible exposure of patients to COVID-19 and redeployment of most transplant healthcare personnel to COVID-19 related areas. Procurement activities for deceased donor transplantation has also been suspended 
since March 13, 2020.

Clinic follow-ups have been replaced by either phone calls, teleconsultations, or social media platforms. COVID-19 in the Philippines poses several challenges. Strict triaging at hospital entry points makes access to hospitals for laboratory testing difficult, while limited availability of reverse transcription polymerase chain reaction (RT-PCR) testing leads to a delay in the results by seven days, affecting it ability to screen patients. Some transplant patients have also reported difficulty in purchasing their anti-rejection drugs, with some having to switch brands of tacrolimus or mycophenolate depending on their availability in the patients' area.

So far, there are six confirmed cases of COVID-19 in kidney transplant recipients and another 15 awaiting results of COVID-19 RT-PCR testing. Only one of the COVID-19 infected kidney transplant patient remains ill and ventilated in the intensive care unit. The rest have recovered with intact graft function. Immunosuppression is reduced for COVID-19 infected patients and even discontinued for those with progressive pneumonia. Treatment for COVID-19 in these patients is varied, with most receiving hydroxychloroquine. However, one patient received lopinavir/ritonavir, while another was treated with tocilizumab with hemoperfusion.

\section{SINGAPORE}

Transplantation programs remain active though services have been significantly reduced $[15,16]$. There are several reasons for this slowdown, which include diversion of manpower and services to COVID-19 related areas, a low supply of blood products due to reduced donations, and rejection of potential deceased donors due to a history of overseas travel and the presence of pneumonia [17]. Notably, heart transplants have stopped because the risks of posttransplant COVID-19 infection is outweighed by the survival benefits of being on left ventricular assist devices. Deceased donors and their recipients are required to undergo serial COVID-19 NAT and CT chest screening [18]. Similarly, living donors and their recipients are required to undergo 14 days of isolation prior to their transplantation procedure and undergo COVID-19 NAT at least 14 days and 1 day before surgery [19]. So far, we have detected COVID-19 in an asymptomatic candidate for deceased donor kidney transplantation as well as in one kidney transplant recipient. Transplant outpatient clinics are increasingly being replaced by video clinics. Referrals for transplantation are reduced but transplant coordinators continue to perform counselling through video conferencing. Evaluation procedures for transplantation have stopped since lockdown on April 4, 2020. We have recently started routine screening for COVID-19 in transplant recipients with gastroenteritis due to recent reports of COVID-19 infected patients presenting primarily with diarrhea. Recently, physicians, surgeons and transplant coordinators have been reassigned to fever triage areas, isolation wards and hospital perimeter screening stations. As a result, the worsening COVID-19 situation in Singapore is likely to lead to a further decline in transplantation activities over time.

\section{SOUTH KOREA}

The initial outbreak in South Korea originated from a mass church service at Daegu, which subsequently prompted massive screening for COVID-19 in targeted populations. As a result, the spread of COVID-19 to other districts has been halted. Unfortunately, the outbreak at Daegu led to shortages in hospital beds, and critically ill patients were transferred to intensive care units located in other provinces of South Korea.

Currently, the curve of the outbreak in South Korea appears to be flattening and South Korea is not currently experiencing shortages in intensive care unit beds. However, there has been a recent increase in cases due to students returning from the United States and Europe.

The Korean Society for Transplantation has released guidelines on COVID-19 and has started prospectively collecting data on transplant recipients infected with COVID-19. So far, there are two kidney transplant recipients infected with COVID-19 in Daegu. At the moment, most transplant programs are active with appropriate precautions. However, highly sensitized cases are being postponed in some centers. Deceased donors are screened for COVID-19 while COVID-19 screening for living donors are performed at the discretion of individual centers. Transplant recipients are also screened for COVID-19 if there are epidemiological links or when respiratory symptoms are present.

Waitlisted patients and transplant recipients are still being followed up, though the frequency of hospital vis- 
its is dependent on the practices of individual centers. Patients are screened for any epidemiological links to COVID-19 before entering the transplant clinics, where those who are COVID-19 suspects are channeled to separate entrances to the hospitals.

\section{CONCLUSION}

At this point in time, most countries that participated in this report are still continuing transplantation activities, but selectively and with protocols to screen for COVID-19 infection in donors and recipients. However, the prevalence of transplantation activities has decreased as resources are diverted to combat COVID-19. Follow-ups of the prevalent transplant population has also decreased in an attempt to reduce their exposure to the community and hospital. Interestingly, only five of the 10 countries participating in this report have reported COVID-19 infections in a total 16 patients. It is unclear whether the low frequency of COVID-19 infections is due to precautionary measures being taken more seriously by patients or due to most COVID-19 infections being milder in immunosuppressed patients, with these patients thus being less likely to present to healthcare providers.

Further effects of the COVID-19 pandemic on the transplantation community may include a significant proportion of wait-listed patients possibly dying due to a lack of access to transplantation. This would be an issue that will need to be addressed if the COVID-19 pandemic does not decline in severity and prevalence. Interestingly, COVID-19 survivors may become transplant candidates, with one center reporting the possibility of performing lung transplantation for survivors with COVID-19-related fibrotic lung disease [20].

As the COVID-19 pandemic has led to extremely dynamic situations, it is important for transplant communities, such as the AST, to develop platforms for countries to continue to share their experience, protocols and information on COVID-19 and transplantation. As a result, the AST is setting up an Asian COVID-19 transplant registry to enable Asian countries to prospectively input data regarding COVID-19 infections.

\section{ACKNOWLEDGMENTS}

\section{Conflict of Interest}

No potential conflict of interest relevant to this article was reported.

\section{ORCID}

Terence Kee https://orcid.org/0000-0002-2553-766X Jong Cheol Jeong

https://orcid.org/0000-0003-0301-7644

Jongwon Ha https://orcid.org/0000-0003-2285-3517

Harun Ur Rashid https://orcid.org/0000-0002-9774-2363

Nura Afza Salma Begum

https://orcid.org/0000-0002-5732-0043

Maggie K.M. Ma https://orcid.org/0000-0002-7784-8494

Vivek Kute https://orcid.org/0000-0002-0002-2854

Kenji Yuzawa https://orcid.org/0000-0002-8357-5664

Rosnawati Yahya https://orcid.org/0000-0002-1347-5318

Ghazali Ahmad https://orcid.org/0000-0001-5084-594X

Lkhaakhuu Od-Erdene

https://orcid.org/0000-0001-9410-6284

Dibya Singh Shah

https://orcid.org/0000-0003-0833-5887

Romina A Danguilan

https://orcid.org/0000-0003-3686-417X

Curie Ahn https://orcid.org/0000-0001-7033-1102

Devinder Singh Rana

https://orcid.org/0000-0001-6622-6975

\section{Author Contributions}

Conceptualization: TK. Data curation: all authors. Formal analysis: all authors. Methodology: TK, VK. Project administration: GA, CA, DSR. Writing-original draft: TK. Writingreview \& editing: all authors.

\section{REFERENCES}

1. World Health Organization. Coronavirus disease (COVID-2019) situation report 81 [Internet]. Geneva: World Health Organization; 2020 [cited 2020 Jun 11]. Available from: https://www.who.int/emergencies/ diseases/novel-coronavirus-2019/situation-reports.

2. Zhang $H$, Chen $Y$, Yuan $Q$, Xia QX, Zeng XP, Peng JT, et al. Identification of kidney transplant recipients with coronavirus disease 2019. Eur Urol 2020;77:742-7.

3. Huang J, Lin $\mathrm{H}, \mathrm{Wu} Y$, Fang $\mathrm{Y}$, Kumar R, Chen G, et al. 
COVID-19 in post-transplantation patients: report of two cases. Am J Transplant 2020 Apr 3 [Epub]. https://doi.org/10.1111/ajt.15896.

4. Wang J, Li X, Cao G, Wu X, Wang Z, Yan T. COVID-19 in a kidney transplant patient. Eur Urol 2020;77:769-70.

5. Chen S, Yin Q, Shi H, Du D, Chang S, Ni L, et al. A familial cluster, including a kidney transplant recipient, of Coronavirus Disease 2019 (COVID-19) in Wuhan, China. Am J Transplant 2020 Apr 3 [Epub]. https://doi. org/10.1111/ajt.15903.

6. Seminari E, Colaneri M, Sambo M, Gallazzi I, Di Matteo A, Roda S, et al. SARS Cov-2 infection in a renal-transplanted patient: a case report. Am J Transplant 2020 Apr 3 [Epub]. https://doi.org/10.1111/ajt.15902.

7. Gandolfini I, Delsante M, Fiaccadori E, Zaza G, Manenti L, Degli Antoni A, et al. COVID-19 in kidney transplant recipients. Am J Transplant 2020 Mar 31 [Epub]. https://doi.org/10.1111/ajt.15891.

8. Zhu L, Xu X, Ma K, Yang J, Guan H, Chen S, et al. Successful recovery of COVID-19 pneumonia in a renal transplant recipient with long-term immunosuppression. Am J Transplant 2020 Mar 17 [Epub]. https://doi.org/10.1111/ ajt.15869.

9. Alberici F, Delbarba E, Manenti C, Econimo L, Valerio F, Pola A, et al. A single center observational study of the clinical characteristics and short-term outcome of 20 kidney transplant patients admitted for SARS-CoV2 pneumonia. Kidney Int 2020;97:1083-8.

10. Guillen E, Pineiro GJ, Revuelta I, Rodriguez D, Bodro M, Moreno A, et al. Case report of COVID-19 in a kidney transplant recipient: does immunosuppression alter the clinical presentation? Am J Transplant 2020 Mar 20 [Epub]. https://doi.org/10.1111/ajt.15874.

11. Li F, Cai J, Dong N. First cases of COVID-19 in heart transplantation from China. J Heart Lung Transplant 2020;39:496-7.

12. Huang JF, Zheng KI, George J, Gao HN, Wei RN, Yan $\mathrm{HD}$, et al. Fatal outcome in a liver transplant recipient with COVID-19. Am J Transplant 2020 Apr 10 [Epub]. https://doi.org/10.1111/ajt.15909.

13. Liu B, Wang Y, Zhao Y, Shi H, Zeng F, Chen Z. Successful treatment of severe COVID-19 pneumonia in a liver transplant recipient. Am J Transplant 2020 Apr 3 [Epub]. https://doi.org/10.1111/ajt.15901.

14. Ministry of Health and Family Welfare, Government of India. Training resources for COVID 19 management [Internet]. New Delhi: Ministry of Health and Family Welfare, Government of India; 2020 [cited 2020 Jun 11]. https://www.mohfw.gov.in/pdf/TrainingresourcesforCOVID1930MARCH.pdf.

15. Wong JE, Leo YS, Tan CC. COVID-19 in Singapore: current experience: critical global issues that require attention and action. JAMA 2020 Feb 20 [Epub]. https:// doi.org/10.1001/jama.2020.2467.

16. Lee VJ, Chiew CJ, Khong WX. Interrupting transmission of COVID-19: lessons from containment efforts in Singapore. J Travel Med 2020;27:taaa039.

17. Lee CC, Thampi S, Lewin B, Lim TJ, Rippin B, Wong WH, et al. Battling COVID-19: critical care and peri-operative healthcare resource management strategies in a tertiary academic medical centre in Singapore. Anaesthesia 2020;75:861-71.

18. Chung SJ, Tan EK, Kee T, Krishnamoorthy TL, Phua GC, Sewa DW, et al. Practical considerations for solid organ transplantation during the COVID-19 global outbreak: the experience from Singapore. Transplant Direct 2020;6:e554.

19. Ho QY, Chung SJ, Gan VH, Ng LG, Tan BH, Kee TY. High-immunological risk living donor renal transplant during the COVID-19 outbreak: uncertainties and ethical dilemmas. Am J Transplant 2020 Apr 26 [Epub]. https://doi.org/10.1111/ajt.15949.

20. Chen JY, Qiao K, Liu F, Wu B, Xu X, Jiao GQ, et al. Lung transplantation as therapeutic option in acute respiratory distress syndrome for COVID-19-related pulmonary fibrosis. Chin Med J (Engl) 2020 Apr 1 [Epub]. https://doi.org/10.1097/CM9.0000000000000839. 